\title{
Ensino Inclusivo de Pensamento Computacional: um Relato de Experiência
}

\author{
Natália Francisco da Silva1, Igor Brito dos Santos ${ }^{1}$, Luís Fernando Orleans ${ }^{1}$ \\ ${ }^{1}$ Departamento de Ciência da Computação - Instituto Multidisciplinar - Universidade Federal \\ Rural do Rio de Janeiro (UFRRJ) - Rio de Janeiro - Brasil \\ natalia-321s@outlook.com, \{britoigor77, lforleans\}@gmail.com
}

\begin{abstract}
This paper objective is to present the experiences acquired at the Computação para Todos project, which seeks to teach fundamentals of Computational Thinking (CT) to elementary school children, in an inclusive way. An initial methodology was tested and adapted, to students with special needs receive the same content as students without these needs. The classes showed contents of Unplugged Computing, Block Programming and Python. Preliminary results showed that the approach used in Block Programming was not crucial to learning Python, and, besides CT skills, skills such as concentration, memory and organization were also stimulated and improved, including for students with special needs. The current phase of the project consists of the elaboration of a course for teachers and professionals in education, of continuing training in $C T$, based on the experiences lived during the creation and test of the initial inclusive methodology
\end{abstract}

Resumo. O objetivo deste trabalho é apresentar experiências adquiridas no projeto Computação para Todos, que busca ensinar fundamentos do Pensamento Computacional (PC) a crianças do ensino fundamental, de forma inclusiva. Uma metodologia inicial foi testada e adaptada, para que alunos com necessidades especiais recebessem o mesmo conteúdo que alunos sem estas necessidades. As aulas mostraram conteúdos de Computação Desplugada, programação com blocos e Python. Resultados preliminares mostraram que a abordagem usada em programação com blocos não foi crucial para aprender Python, e que, além de habilidades de PC, habilidades como concentração, memória e organização também foram estimuladas e aprimoradas, inclusive nos alunos com necessidades especiais. A fase atual do projeto consiste na elaboração de um curso, para professores e profissionais da educação, de formação continuada em PC, baseando-se nas experiências vivenciadas durante a criação e teste da metodologia inclusiva inicial.

\section{Introdução}

Neste artigo é apresentado um relato de experiência sobre o projeto Computação para Todos, que tem por principal objetivo o desenvolvimento de uma metodologia inclusiva para o ensino de Pensamento Computacional (PC) a crianças do ensino fundamental, com idade entre 10 e 12 anos. A participação de alunos com necessidades especiais foi essencial, e planejada desde o início, e para isso, vagas foram reservadas para tais alunos. Cabe ressaltar que, para este trabalho, foi utilizada a definição de PC apresentada em Mannila et al. (2014), que define PC como um termo que consiste na abrangência de um conjunto de conceitos e 
processos mentais que ajudam na formulação de problemas e em suas soluções em diferentes campos de um jeito que podem ser envolvidos computadores. Também foi utilizada a definição encontrada em Wing (2016), onde o PC é considerado uma habilidade fundamental, e não exclusiva aos cientistas da Computação, que envolve solucionar problemas com base nos conceitos fundamentais de Ciência da Computação.

Este trabalho está estruturado da seguinte forma: na seção 2 deste artigo é apresentada uma breve introdução ao Pensamento Computacional, mostrando o conceito, e também suas divisões. Já na seção 3, há informações sobre o desenvolvimento e detalhes do projeto. Em seguida, há a seção 4, que apresentando a metodologia aplicada. Logo após, temos a seção 5, trazendo trabalhos relacionados, e em seguida há a seção 6, que aborda as considerações finais e trabalhos futuros. Por fim, a seção 7 contém as referências.

Cabe ressaltar que a seção contendo os trabalhos relacionados está depois das seções 3 e 4, onde são explicados e detalhados o projeto e a metodologia, para evitar repetição desnecessária de informação.

\section{Pensamento Computacional}

O conceito de Pensamento Computacional vai muito além de saber usar o computador para tarefas básicas como editar um documento ou acessar sites de pesquisa. A ideia do Pensamento Computacional é encontrar maneiras de resolver problemas diversos usando conceitos da Computação como ferramenta. Conforme (Gomes et al., 2013), pela aplicabilidade do PC em variados tipos de problemas, esta capacidade se mostra fundamental para as pessoas em geral, e não somente para pessoas que estudam ou trabalham com Ciência da Computação.

Assim como Mannila et al. (2014) explica, há nove conceitos essenciais do Pensamento Computacional. São eles: coleta, análise, representação de dados, decomposição de problemas, abstração, algoritmos, automação, paralelismo e simulação. Um dos principais objetivos do Computação para Todos é fazer com que os alunos evoluam estas habilidades através de atividades lúdicas planejadas por uma equipe pedagógica em parceria com uma equipe de Ciência da Computação.

No Brasil, há inúmeras iniciativas surgindo em relação ao incentivo de disciplinas de lógica e/ou Pensamento Computacional nas escolas, não só para crianças, mas também para alunos do ensino médio. Trabalhos como o apresentado por Gomes et al. (2017) trazem resultados interessantes sobre o uso de elementos de jogos para a introdução à programação. Em (Ribeiro et al., 2017), percebemos a proposta do uso de programação por manipulação de imagens para auxiliar no ensino médio e técnico. O uso de Gamificação juntamente com Storytelling no ensino fundamental é apresentado por de Melo Reis et al. (2017). Com todos estes trabalhos publicados e diversos outros, podemos ter esperança de que o interesse pela disseminação do ensino do Pensamento Computacional tenda a crescer ao longo dos anos.

\subsection{Computação Desplugada}

Computação Desplugada, que é o termo que define a resolução de problemas diversos sem uso de um computador, assim como em Bell et al. (2008). Outra definição de Computação Desplugada (CD) interessante é a de Queiroz et al. (2016), que afirma que CD ensina fundamentos da computação de maneira lúdica e sem a preocupação de lidar com detalhes técnicos. Pelo fato de não necessitar um computador para ser aplicada, a Computação Desplugada é uma ótima forma de evoluir o PC em escolas de ensino fundamental e médio 
onde recursos tecnológicos sejam precários ou inexistentes. Apesar de ser extremamente útil e de custo não tão alto, a CD não é praticada de forma perceptível e divulgada nas escolas brasileiras. Na literatura também há a escassez de publicações e estudos sobre a área de Pensamento Computacional juntamente com CD, de acordo com Brackmann et al. (2017), mesmo sendo uma abordagem mais acessível do que o ensino de PC com linguagem de programação e o ensino de PB.

Atividades baseadas em CD podem ajudar no desenvolvimento e treinamento das habilidades essenciais do PC, que são: coleta, análise e representação de dados, decomposição de problemas, abstração, pensamento algorítmico, automação, paralelismo e simulação [Mannila et al. 2014]. Entretanto, habilidades como simulação, por exemplo, podem gerar dificuldades quanto à adaptação de uma atividade que não utilize computadores e dispositivos eletrônicos deste tipo.

\subsection{Programação por Blocos}

A programação por blocos vem se mostrando cada vez mais uma ótima maneira de estimular habilidades de Pensamento Computacional (PC) em alunos em geral, e sua abordagem lúdica e menos complicada que a sintaxe de uma linguagem de programação comum atrai boa parte dos alunos do ensino fundamental que tem contato com o ensino de informática e/ou computação. A programação por blocos (PB) conta com diversas ferramentas disponíveis, alguns exemplos são Kodu [Stolee 2010] voltada para desenvolvimento de jogos, Alice [alice.org 2017] onde é possível criar animações, narrativas interativas ou até mesmo jogos em 3D, App Inventor [MIT app Inventor 2017] ferramenta focada na criação de aplicativos Android, e Scratch [Resnick et al. 2009], criada pelo Massachusetts Institute of Technology (MIT), que é uma linguagem para ensinar programação a crianças.

Geralmente o uso de ferramentas de PB é usado para promover noções básicas de raciocínio lógico e desenvolvimento da capacidade de abstração em alunos tanto do fundamental como do ensino médio [Resnick et al. 2009].

\subsection{Programação com Python}

O primeiro contato com uma linguagem de programação deve ser o menos complicado possível, e tal fato deve ser levado ainda mais em consideração devido aos constantes problemas de desmotivação, reprovação e abandono precoce, enfrentados em cursos da área da Computação no cenário atual.

Tais problemas, em grande medida, se relacionam com a dificuldade em aprender a programar a partir de uma metodologia tradicional, onde apresenta-se o conteúdo e os estudantes devem resolver listas de exercícios. Estes exercícios são, em sua maioria, dissociados das vidas dos alunos, o que os leva a achar a programação enfadonha e excessivamente técnica [Guzdial 2003].

O Python é uma linguagem de programação que apresenta como algumas das principais características, a legibilidade e produtividade, ou seja, produzir códigos de maneira rápida e de fácil compreensão. Tais características, somadas ao fato de ser uma linguagem altamente utilizada comercialmente à tornam uma linguagem adequada às necessidades dos programadores iniciantes.

\section{Projeto Computação para Todos}


A equipe do projeto é multidisciplinar, contendo pesquisadores e alunos bolsistas tanto de Ciência da Computação como de Pedagogia, e esta característica foi a principal responsável pelo sucesso do projeto até o momento.

O projeto recebeu duas turmas de nove alunos, em dois momentos distintos, com sequências didáticas diferentes. A seleção dos alunos de ambas as turmas foi feita através de edital público. A seguir, a composição de cada uma das turmas é descrita, deixando evidente o caráter inclusivo do projeto.

\subsection{Turma 1}

A primeira turma contou com nove alunos, todos estudantes do ensino fundamental e com idades entre nove e doze anos. Dentre estes, havia um aluno com autismo, outro com deficiência intelectual, e outro com superdotação/altas habilidades diagnosticada por especialista. Esta turma recebeu primeiramente aulas de Computação Desplugada [Bell et al. 2011], em seguida, aulas Programação com blocos (PB), com auxílio da ferramenta Scratch [Resnick et al. 2009], e, por fim, tiveram aulas de programação com Python ${ }^{1}$ durante o primeiro semestre de 2018. Esta primeira turma teve aulas durante dois semestres (2017-2 e 2018-1), com carga horária de 60 horas para cada semestre. No segundo semestre de aulas desta turma, uma novidade foi a adição de aulas com conteúdos combinados, onde era necessário encontrar uma solução para um problema, tanto em Scratch como em Python. Deste modo, os alunos tiveram a chance de ver que conceitos vistos em PB podiam ser facilmente utilizados para programar na linguagem Python.

\subsection{Turma 2}

A segunda turma, também com nove alunos, das mesmas faixas etária e escolar, onde três deles possuem autismo e um possui Transtorno do Déficit de Atenção com Hiperatividade (TDAH). Esta turma teve aulas durante um semestre (2018-1), com carga horária de 60 horas, e contou somente com aulas de CD e Python, com os mesmos conteúdos da primeira turma, apenas com melhorias na forma como os tópicos eram apresentados. A principal diferença se deu na criação de atividades "combinadas" (AC), onde um problema era apresentado em CD e, na mesma aula, as crianças programavam suas soluções em Python.

Como semelhança, crianças das mais diversas faixas sociais estiveram presentes em ambas as turmas. Além do caráter inclusivo evidente, esta característica se apresentou como um desafio, pois algumas crianças sequer possuíam computadores em casa para praticar os conteúdos.

\section{Metodologia desenvolvida}

A metodologia empregada consistiu em aulas de Computação Desplugada, Programação em blocos e Python, nesta respectiva ordem. Porém, para fins de comparação, uma das duas turmas não recebeu aulas de $\mathrm{PB}$, passando de $\mathrm{CD}$ diretamente para Python.

A metodologia desenvolvida foi baseada no conceito de Desenho Universal para Aprendizagem, que estabelece o projeto de artefatos, metodologias e objetos pedagógicos para serem utilizados por pessoas com ou sem deficiências, evitando, desta forma, a diferenciação curricular [Pletsch, et al. 2017]. Assim, o caráter inclusivo deste projeto ocorre

\footnotetext{
1 "Python.org." https://www.python.org/. Acessado em 23 Mar. 2019.
} 
ao inserirmos, na mesma sala de aula e acompanhando o mesmo conteúdo, crianças com e sem deficiências.

Nas atividades de Computação Desplugada (CD), os tópicos foram apresentados de maneira lúdica, a fim de manter as crianças animadas ao longo das aulas. Os alunos tiveram contato com temas como números binários, representação de imagens, detecção e correção de erros, algoritmos de busca, algoritmos de ordenação, redes de ordenação, árvores geradoras mínimas, e roteamento e bloqueio nas redes. Grande parte das atividades promoveu a interação entre as crianças, evitando assim que houvesse exclusão entre elas e estimulando a comunicação e trabalho em equipe. Nestas atividades, as crianças eram encorajadas a encontrar por elas mesmas as soluções para os variados problemas. Durante as aulas de CD, através das atividades crianças as aprenderam a:

- descrever um problema,

- identificar os detalhes mais importantes que estavam relacionados ao problema,

- reduzir o problema a pequenos passos lógicos,

- usar esses passos para criar um processo (algoritmo) que resolva o problema,

- avaliar este processo (algoritmo).

Já nas atividades de $\mathrm{PB}$, os alunos ganharam liberdade para explorar a ferramenta Scratch. A técnica escolhida para o ensino de PC com programação por blocos foi storytelling, que se trata de contação de histórias que tenham alguma interação com o público, segundo da Silva et al. (2017). Como tarefa final desta etapa, cada aluno elaborou uma história que continha um enigma a ser resolvido. Os próprios alunos ficaram responsáveis pelas definições de seus enigmas. Todas as crianças receberam ajuda com o uso da ferramenta, mas suas histórias sofreram o mínimo de interferência possível por meio da equipe do projeto. Sendo assim, cada um usou coisas diferentes ao montar sua história, e com isso, cada aluno teve seu próprio ritmo. Estas duas primeiras sequências de atividades ocorreram durante o semestre 2017-2.

Por fim, durante o semestre 2018-1, a turma 1 teve aulas de programação em Python, onde foram abordados conteúdos básicos e necessários em qualquer linguagem de programação, como entrada e saída de dados, operadores, variáveis, laços, condições, operadores condicionais, e funções. Ainda no semestre de 2018-1, os alunos tiveram a chance de experimentar algumas atividades "combinadas", onde resolviam problemas em Python e depois reproduziam a solução no Scratch, e vice versa. Além disso, também foram apresentados o módulo turtle (gráficos tartaruga), usado para desenhar utilizando conjuntos de funções, e a biblioteca PyGame [pygame.org 2019], usada para desenvolvimento de jogos. Todas as aulas foram interativas e aconteceram em laboratórios equipados com computadores com a IDE (Ambiente de Desenvolvimento Integrado) padrão da linguagem Python (IDLE).

No Computação para Todos, as aulas de programação com Python foram elaboradas pela equipe de Ciência da Computação, com o auxílio da equipe pedagógica. Tais aulas eram modeladas levando em consideração a busca por exemplos e exercícios contendo imagens e animações, e principalmente, com enunciados atrativos à faixa etária dos alunos. Nunca esquecendo de analisar quais pilares do PC seriam trabalhados em cada aula. Dessa forma, uma aula mais atrativa era montada, levando em consideração que uma aula de programação extensa, e com exercícios complexos certamente ocasionaria desinteresse aos alunos.

No processo de elaboração das aulas, sempre haviam instruções da equipe pedagógica em relação à escolha dos enunciados, à forma em que os comandos da linguagem Python seriam explicados, ao grau de dificuldade do exercícios, e até mesmo ao vocabulário dos 
professores, a fim de incluir as crianças com necessidades especiais no contexto das aulas, sem prejudicar o andamento das mesmas.

O planejamento das aulas e preparação dos materiais usados em sala de aula foi feito por ambas as equipes. Integrantes de Computação cuidando dos conteúdos e integrantes do curso de Pedagogia buscando melhorar a didática, exemplos, e dinâmica das aulas. Para as aulas de $\mathrm{CD}$, reuniões eram marcadas antes de cada aula, e nestas reuniões eram discutidas as melhores formas de abordar cada conteúdo e como conduzir as atividades. Também eram resolvidas questões como confecção de materiais a serem utilizados, onde estes materiais poderiam ser folhas de atividades ou até mesmo cartões de papel para alguma atividade mais interativa. Para as aulas de $\mathrm{PB}$, não era necessário materiais adicionais, portanto o planejamento se tratava apenas de como conduzir o processo de storytelling, a fim de manter a produtividade dos alunos e os prazos do projeto.

Por fim, para as aulas de Python, o planejamento se tornou mais complexo do que para as outras abordagens. Inicialmente as apresentações (slides) de cada aula eram fortemente baseadas no livro de apoio denominado "Ensine Seus Filhos a Programar" escrito por Bryson Payne (2015). Com o decorrer das aulas, o conteúdo selecionado passou por diversas adaptações, para que todas as crianças conseguissem acompanhar cada conceito e treinar as habilidades de PC.

A contribuição da equipe pedagógica foi de extrema importância para as crianças e para os bolsistas de Ciência da Computação. A equipe de Pedagogia identificava habilidades exercitadas nas atividades, identificava o comportamento dos alunos e usavam abordagens adequadas para atrair a atenção deles, promovia a interação entre as crianças e lidava também com toda a parte de intervenção pedagógica. Além disso, o auxílio da equipe pedagógica foi essencial para a montagem das apresentações, visto que quando esta equipe passou a ter mais participação na confecção dos slides, o entendimento dos alunos sobre os assuntos tratados aconteceu mais facilmente. Segue abaixo um exemplo de como as sugestões e revisões pedagógicas impactaram no resultado final de cada apresentação. Onde a Figura 1 mostra uma página da apresentação sobre condicionais e expressões booleanas em Python, e a Figura 2 mostra como esta página ficou após alterações sugeridas pela equipe pedagógica.

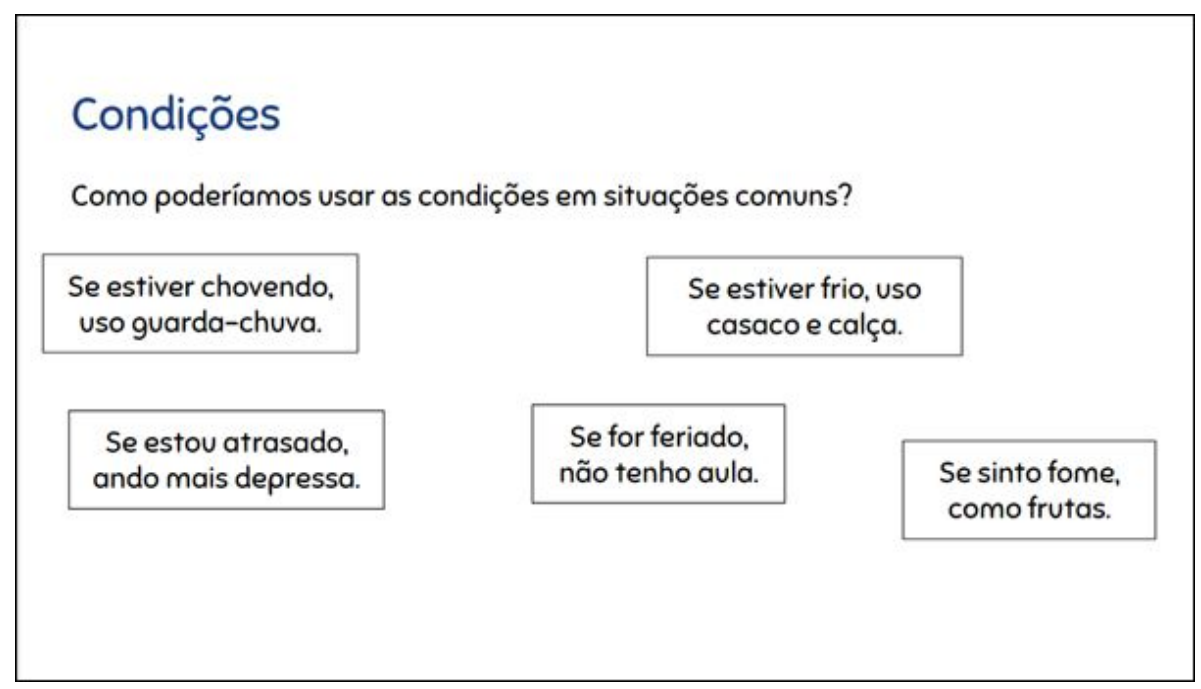

Figura 1. Página retirada do material de Python usado em sala 


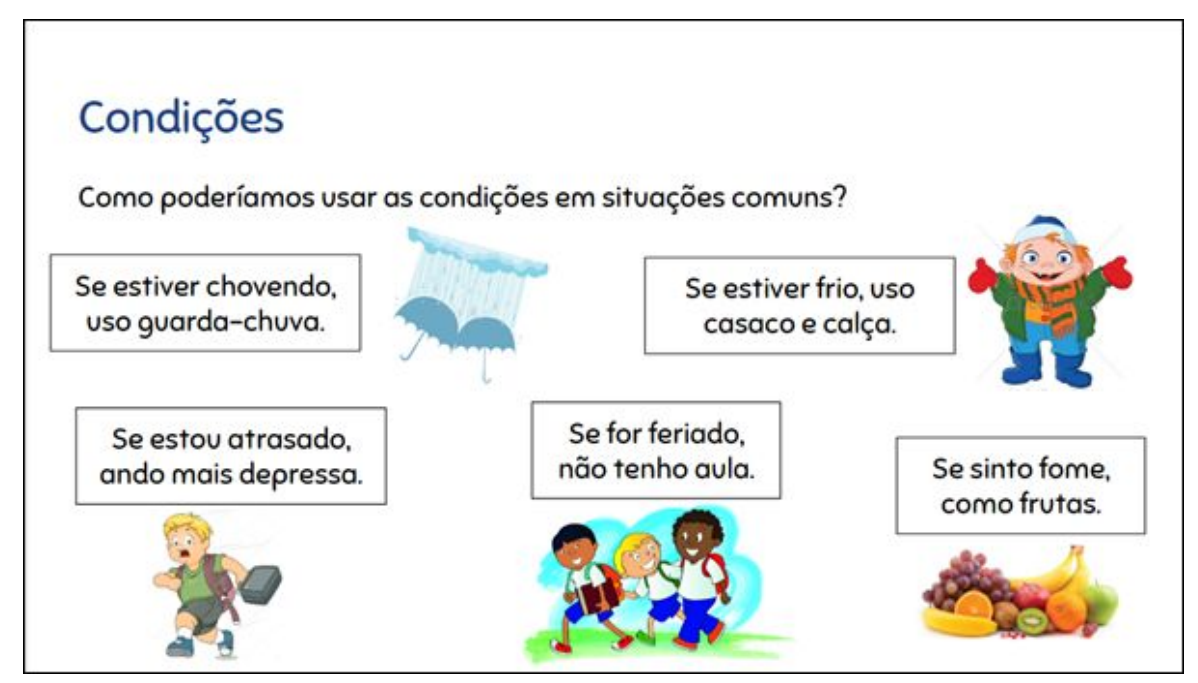

Figura 2. Resultado das alterações feitas no material

Foram encontrados alguns pequenos problemas de aprendizado durante o decorrer do projeto, como por exemplo:

- Dificuldade de entendimento por parte dos alunos em determinados conteúdos: para contornar este tipo de problema, exemplos eram adaptados para algo mais próximo da realidade dos alunos, como mostrado nas figuras 1 e 2 . Durante a experiência do projeto, ficou claro que atividades com exemplos complexos ou muito extensos dificultavam tanto a explicação do tema tratado como as soluções propostas pelos alunos.

- Crianças com dificuldades quanto ao uso do computador: isto foi resolvido com apoio da equipe pedagógica e da equipe de Computação de cada turma, que auxiliava cada aluno com dúvidas deste tipo. Lembrando que, pela pequena quantidade de alunos por turma, este problema não foi de difícil resolução.

- Crianças não possuíam computadores em casa para praticar os conteúdos: as aulas das duas turmas ocorriam semanalmente, o ideal seria que cada aluno conseguisse explorar mais os conteúdos vistos em sala, praticar tanto PB quanto Python, trazer dúvidas e compartilhá-las com os colegas. Porém, isso não era possível para as crianças que não possuíam computadores em suas casas.

- Número de faltas: houve casos de alunos que faltaram mais de uma aula consecutivamente, prejudicando o entendimento de conceitos importantes. Uma solução para minimizar o impacto das faltas consistiu em recapitular os tópicos mais relevantes da aula anterior junto com as crianças.

- Comandos de Python em inglês: este detalhe dificultou o entendimento de alguns alunos, porém isso foi contornado aos poucos, conforme cada criança se habituava à linguagem.

\subsection{Desafio final}

Ao final do semestre 2018-1, foi elaborado um único desafio de programação em Python para as duas turmas, onde as crianças deveriam terminar um jogo previamente desenvolvido pela equipe de Computação. Todas as crianças tiveram o mesmo tempo para finalizar o jogo (4 horas). A finalização do jogo foi pensada de forma que fosse necessário utilizar conceitos vistos durante as aulas. Todos os alunos conseguiram finalizar o jogo, e apenas as duas crianças com dificuldades mais severas de aprendizagem (uma de cada turma) precisaram da intervenção da equipe pedagógica. 


\section{Trabalhos Relacionados}

Quanto ao ensino de PC usando CD, um projeto parecido foi encontrado em Brackmann et al. (2017). No projeto referido, a aplicação ocorre em duas escolas primárias localizadas na Espanha, onde a faixa etária dos alunos participantes é de 10 a 12 anos. Ao analisar os resultados apresentados no relato é possível ver que o uso de atividades desplugadas teve um efeito positivo no rendimento dos participantes.

Werlich et al. (2018) apresenta um estudo de caso onde o PC é abordado com uma atividade de $\mathrm{CD}$, para crianças do primeiro e segundo ano do ensino fundamental. A atividade proposta pede que as crianças encontrem uma rota que passe por todos os pontos solicitados, desviando de obstáculos e tentando minimizar a solução. De acordo com a publicação, tal atividade primeiramente foi aplicada individualmente e em seguida em grupos de quatro crianças. Ao final, é constatado que a atividade funcionou melhor individualmente para a turma do primeiro ano, e trabalhar em equipes foi melhor para o segundo ano.

O trabalho de Duarte et al. (2017) mostra uma iniciativa parecida com a apresentada neste trabalho. Porém, além do referido projeto ter sido aplicado em duas escolas, e com menor quantidade de aulas de PB, não há nenhuma informação sobre uma metodologia inclusiva e acessível a alunos com algum tipo de deficiência.

Outro projeto com metodologia parecida é apresentado em Batista et al. (2017), onde a proposta é o uso de programação com blocos, com auxílio da ferramenta Poredu, para incentivar o ensino de programação e de robótica para crianças a partir de oito anos. Assim como no caso anterior, apesar dos esforços para a possível inserção de disciplinas e exercícios de raciocínio lógico e programação para crianças, não há ainda a preocupação com a questão da acessibilidade para alunos com necessidades especiais.

No artigo de Torres et al. (2018) são encontradas algumas semelhanças com o Computação para Todos na parte de ferramentas e abordagens usadas. Em seu artigo, Torres traz um relato sobre um curso de PC no interior da Paraíba, para estudantes do ensino médio. Neste curso o PC foi abordado através de Scratch e da linguagem de programação Librelogo, onde a escolha destas duas ferramentas se justificam pelo fato de serem de fácil acesso, instalação e utilização. Analisando questionários, Torres conclui que o desempenho escolar dos participantes do curso melhorou. Comparando esta iniciativa com o projeto Computação para Todos, pode-se notar que a maior diferença está no fato do uso de CD e da preocupação com a inclusão de alunos com necessidades especiais.

O trabalho em LG Araújo et al. (2017) se assemelha a iniciativa deste projeto ao utilizar a linguagem de programação Python como meio de facilitar a aprendizagem e motivar os estudantes a se manterem na área computacional. No entanto, este foi aplicado à uma turma de terceiro ano de um Curso Técnico em Informática, apresentando uma diferença na faixa etária das turmas em relação ao Computação para Todos, e não apresentou uma metodologia inclusiva e acessível a alunos com algum tipo de deficiência.

Não foram encontrados resultados em relação a projetos que utilizem a linguagem de programação Python para a formação do PC para alunos da faixa etária deste projeto (entre dez e doze anos) e que façam a inclusão de crianças com necessidades especiais. Isso também ocorre quando se trata de ensino de PC com uso de CD. Há publicações parecidas com o projeto descrito neste artigo, porém não há informações sobre a inclusão de crianças com necessidades específicas nestas publicações. 
Um dos diferenciais do Computação para Todos é que além de incentivar o ensino de PC na infância, há a preocupação de planejar as aulas de modo inclusivo, a fim de não prejudicar os alunos com necessidades especiais, neste caso, deficiência intelectual, autismo e superdotação/altas habilidades.

Cabe ressaltar, que para estas menções e comparações, foram consideradas apenas publicações divulgadas nos Anais dos Workshops do CBIE (2017 e 2018) e Workshop de Informática na Escola (2017 e 2018).

\section{Considerações Finais e Trabalhos Futuros}

Após dois semestres de atividades, foi possível observar que a inclusão de uma ferramenta de $\mathrm{PB}$, usando a técnica de storytelling, é opcional para o ensino de PC, especialmente quando já existem atividades com a linguagem Python no planejamento. Em nossa vivência, os alunos que não tiveram contato com $\mathrm{PB}$ foram perfeitamente capazes de realizar as mesmas atividades que aqueles que tiveram, apresentando a mesma qualidade nas soluções em Python. Um fato interessante é que, a maioria dos alunos da turma 1 mostrou maior facilidade em construir boas soluções no Scratch após passar por algumas aulas de Python.

As aulas do projeto também foram responsáveis pelo aumento de outras habilidades nas crianças, percebidas pela equipe pedagógica através de análise de questionários de observação e diários de campo. De modo geral, os alunos se mostraram mais concentrados, com maior capacidade de abstração e até mais organizados após o encerramento das aulas.

A etapa atual do projeto é a criação de um curso de formação continuada em PC, voltado para professores e profissionais da educação, de acordo com as experiências obtidas pelas duas equipes. O objetivo é apresentar o PC e mostrar aos educadores os benefícios proporcionados, focando também na inclusão de alunos com necessidades especiais. Além de ensinar como aplicar o PC nas salas de aula, o curso de formação continuada terá aulas e atividades voltadas para criação de atividades, materiais e métodos de avaliação para as abordagens que utilizam CD e PB. Deste modo, seria possível tornar o PC com aulas inclusivas uma coisa mais acessível.

\section{Referências}

Batista, E. J. S., Silva, L., Leite, C., \& Lima, A. (2017, October). Poredu: um ambiente de programação em blocos. In Anais dos Workshops do Congresso Brasileiro de Informática na Educação (Vol. 6, No. 1, p. 144).

Bell, T., Witten, I. H., Fellows, M., Adams, R., \& McKenzie, J. (2011). Ensinando Ciência da Computação sem o uso do computador. Computer Science Unplugged ORG.

Brackmann, Christian, et al. "Pensamento Computacional Desplugado: Ensino e Avaliação na Educação Primária Espanhola." Anais dos Workshops do Congresso Brasileiro de Informática na Educação. Vol. 6. No. 1. 2017.

da Silva, J. A. L., Oliveira, F. C. S., \& Martins, D. J. S. (2017). Storytelling e gamificação como estratégia de motivação no ensino de programação com Python e Minecraft.

de Melo Reis, F., Cristiano, F., Martins, D., \& da Rocha, P. (2017, October). Pensamento Computacional: Uma Proposta de Ensino com Estratégias Diversificadas para Crianças do Ensino Fundamental. In Anais do Workshop de Informática na Escola (Vol. 23, No. 1, p. 638). 
Duarte, K., Silveira, T., \& Borges, M. (2017, October). Abordagem para o Ensino da Lógica de Programação em Escolas do Ensino Fundamental II através da Ferramenta Scratch 2.0. In Anais do Workshop de Informática na Escola (Vol. 23, No. 1, p. 175).

Gomes, T., \& Melo, J. (2013). O Pensamento Computacional no Ensino Médio: Uma Abordagem Blended-Learning. In Anais do XXI Workshop sobre Educação em Computação-XXXIII Congresso da Sociedade Brasileira de Computação. Maceió, AL-Brasil.

Gomes, T., \& Tedesco, P. (2017, October). Gamificando a sala de aula: desafios e possibilidades em uma disciplina experimental de Pensamento Computacional no ensino fundamental. In Anais do Workshop de Informática na Escola (Vol. 23, No. 1, p. 1).

Mannila, L., Dagiene, V., Demo, B., Grgurina, N., Mirolo, C., Rolandsson, L., \& Settle, A. (2014, June). Computational thinking in K-9 education. In Proceedings of the working group reports of the 2014 on innovation \& technology in computer science education conference (pp. 1-29). ACM.

Pletsch, M. D., Souza, F. F. d., and Orleans, L. F. (2017). A diferenciação curricular e o desenho universal na aprendizagem como princípios para a inclusão escolar. Revista Educação e Cultura Contemporânea, 14(35):264-281.

Pygame.org - Pygame Website (2018) Disponível em:<https://www.pygame.org/>. Acesso em 9 de setembro.

Queiroz, R., Sampaio, F. F., \& dos Santos, M. P. (2016, November). DuinoBlocks4Kids: Ensinando conceitos básicos de programação a crianças do Ensino Fundamental I por meio da Robótica Educacional. In Anais dos Workshops do Congresso Brasileiro de Informática na Educação (Vol. 5, No. 1, p. 1169).

Resnick, M., Maloney, J., Monroy-Hernández, A., Rusk, N., Eastmond, E., Brennan, K., ... \& Kafai, Y. (2009). Scratch: programming for all. Communications of the ACM, 52(11), 60-67.

Ribeiro, A. L., Carvalho, I. C., Araújo, L. G., \& Bittencourt, R. (2017, October). Computação com Mídias na Aprendizagem de Programação Orientada a Objetos em um Curso Técnico de Informática. In Anais dos Workshops do Congresso Brasileiro de Informática na Educação (Vol. 6, No. 1, p. 1031).

Stolle, K. (2010) Kodu Language and Grammar Specification. Microsoft Research whitepaper.

Torres, F., Junior, M., Dantas, R., Mascena, L., \& Damasceno, A. (2018, October). Ensinando o pensamento computacional usando linguagens de programação no Alto Sertão da Paraíba. In Anais do Workshop de Informática na Escola (Vol. 24, No. 1, p. $660)$.

Werlich, C., Crema, C., Kemczinski, A., \& Gasparini, I. (2018, October). Pensamento Computacional no Ensino Fundamental I: um estudo de caso utilizando Computação Desplugada. In Anais dos Workshops do Congresso Brasileiro de Informática na Educação (Vol. 7, No. 1, p. 719).

Wing, J. M. (2006). Computational thinking. Communications of the ACM, 49(3), 33-35. 